\title{
Aspirin for primary prevention of cardiovascular events in people with diabetes: meta-analysis of randomised controlled trials
}

\author{
Giorgia De Berardis, research officer, ${ }^{1}$ Michele Sacco, research officer, ${ }^{1}$ Giovanni F M Strippoli, editor and \\ regional coordinator of the Cochrane Renal Group, ${ }^{1,2}$ Fabio Pellegrini, senior biostatistician, ${ }^{1}$ Giusi Graziano, \\ biostatistician, ${ }^{1}$ Gianni Tognoni, institute director, ${ }^{3}$ Antonio Nicolucci, department head ${ }^{1}$
}

\section{${ }^{1}$ Department of Clinical}

Pharmacology and Epidemiology,

Consorzio Mario Negri Sud, Via

Nazionale 8/a, 66030 S. Maria

Imbaro, Italy

${ }^{2}$ Diaverum Medical Scientific Office, Lund, Sweden, School of Public Health, University of

Sydney, Australia, and Cochrane Renal Group, Sydney, Australia

${ }^{3}$ Consorzio Mario Negri Sud, S Maria Imbaro, Italy

Correspondence to: A Nicolucci nicolucci@negrisud.it

Cite this as: $B M J$ 2009;339:b4531 doi:10.1136/bmj.b4531

\section{ABSTRACT}

Objective To evaluate the benefits and harms of low dose aspirin in people with diabetes and no cardiovascular disease.

Design Meta-analysis of randomised controlled trials. Data sources Medline (1966-November 2008), the Cochrane central register of controlled trials (Cochrane Library 2008; issue 4), and reference lists of retrieved articles.

Review methods Randomised trials of aspirin compared with placebo or no aspirin in people with diabetes and no pre-existing cardiovascular disease were eligible for inclusion. Data on major cardiovascular events (death from cardiovascular causes, non-fatal myocardial infarction, non-fatal stroke, and all cause mortality) were extracted and pooled with a random effect model. Results are reported as relative risks with $95 \%$ confidence intervals.

Results Of 157 studies in the literature searches, six were eligible (10117 participants). When aspirin was compared with placebo there was no statistically significant reduction in the risk of major cardiovascular events (five studies, 9584 participants; relative risk 0.90 , $95 \%$ confidence interval 0.81 to 1.00 ), cardiovascular mortality (four studies, $n=8557,0.94 ; 0.72$ to 1.23 ), or all cause mortality (four studies, $n=8557 ; 0.93,0.82$ to

1.05). Significant heterogeneity was found in the analysis for myocardial infarction $\left(I^{2}=62.2 \% ; P=0.02\right)$ and stroke $\left(I^{2}=52.5 \% ; P=0.08\right)$. Aspirin significantly reduced the risk of myocardial infarction in men $(0.57,0.34$ to 0.94$)$ but not in women (1.08, 0.71 to 1.65 ; $P$ for

interaction $=0.056$ ). Evidence relating to harms was inconsistent.

Conclusions A clear benefit of aspirin in the primary prevention of major cardiovascular events in people with diabetes remains unproved. Sex may be an important effect modifier. Toxicity is to be explored further.

\section{INTRODUCTION}

Aspirin is recommended by key guideline agencies for the primary prevention of cardiovascular events in people with diabetes, although with some inconsistencies (see web extra on bmj.com). ${ }^{1-6}$ Existing recommendations are primarily based on indirect evidence extrapolated from large trials of populations at high risk of cardiovascular events. ${ }^{1-6}$ Evidence supporting the efficacy of aspirin therapy in trials of only people with diabetes is scant. A previous meta-analysis (287 trials, 135000 participants) on the efficacy of antiplatelet therapy in the prevention of major cardiovascular events found a clear benefit of aspirin overall, but no statistically significant benefit in the subgroup of only people with diabetes (nine trials, 5126 participants). ${ }^{7}$ No significant reduction in the risk of major cardiovascular events with low dose aspirin compared with placebo was found in three additional trials published after that meta-analysis. ${ }^{8-10}$

Reactions of many in the scientific and clinical community to the results of the most recent trials have been mixed, some arguing for definite proof on the lack of aspirin's efficacy in the primary prevention of cardiovascular events, ${ }^{11}$ others raising claims that data are still inconclusive and more trials are warranted. ${ }^{12}{ }^{13}$ The persisting uncertainties form the basis of our meta-analysis of trials on the benefits and harms of aspirin in people with diabetes and no pre-existing cardiovascular disease.

\section{METHODS}

We included prospective, randomised, controlled, open or blinded trials of participants with diabetes mellitus who were allocated to aspirin treatment or a control group (placebo or no treatment) for the primary prevention of cardiovascular disease. The outcomes of interest were all cause mortality, death from cardiovascular causes, non-fatal myocardial infarction, and non-fatal stroke.

We also included data on subsets of people with diabetes who were enrolled in larger studies of the general population or patients with a mixed baseline risk for cardiovascular events, where aspirin was tested against placebo or no treatment. 
Data sources, searches, and extraction

Using the terms diabetes mellitus and aspirin and a filter highly sensitive for randomised controlled trials only, we searched Medline (1966-November 2008) for trials of people with diabetes who received aspirin. A filter for studies in humans was also used and only trials of more than 500 participants were eligible. We also searched the Cochrane central register of controlled trials (Cochrane Library 2008;issue 4) for studies meeting these criteria. ${ }^{14}$ Searches were limited to published English language articles. Reference lists of identified trials and review articles were also searched for additional published data on the topic.

Two authors independently reviewed results of the search strategies and identified eligible trials; data extraction was done independently by the same authors using a predefined form. Information was collected on study design; study sample; characteristics of the populations, including the proportion of men and women enrolled; interventions; the methodological quality of the trials; and the outcomes of all cause mortality, fatal or non-fatal cardiovascular and cerebrovascular events (defined as myocardial infarction, stroke, or composites of these end points); any bleeding, gastrointestinal bleeding, gastrointestinal symptoms, and incidence of cancer; withdrawals for any reason; and proportion of patients lost to follow-up. Discrepancies between the two reviewers were resolved through discussion and consensus, with an arbitrator.

\section{Quality assessment of methods}

Methodological quality of included randomised controlled trials was assessed by several domains: allocation concealment (considered adequate if randomisation method was described such that it would not allow the investigator or participant to know or influence the intervention group before eligible participants had entered the study; unclear if randomisation was stated but no information on method used was available; inadequate when the study used a method of randomization such as alternation, medical record numbers, date of birth, or unsealed envelopes, or if any information in the study indicated that investigators or participants could influence allocation to the experimental or control group); blinding of investigators, participants, and outcome assessors; use of intention to treat analysis; completeness of follow-up. Discrepancies in data extraction between the two reviewers were resolved by discussion and consensus, with an arbitrator.

\section{Statistical analysis}

We compared treatments using relative risks with $95 \%$ confidence intervals. Heterogeneity between studies was assessed with the Cochran's $Q$ and the $I^{2}$ statistics. ${ }^{15}$ A random effects meta-analysis ${ }^{16}$ was used to estimate overall relative risks. The influence of potential sources of heterogeneity on treatment effects was explored by subgroup analysis. The following characteristics of the population, intervention, and

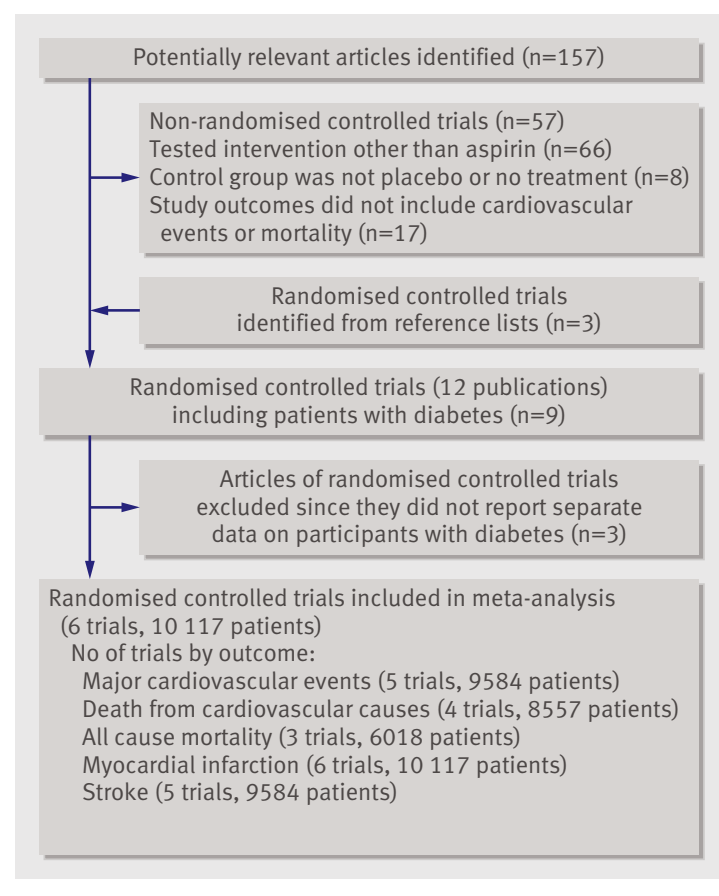

\section{Fig 1| Flow of trial selection process}

methodological quality of the trials were defined a priori as potential effect modifiers: sex, dose of aspirin, duration of treatment, allocation concealment, and compliance with treatment. Analyses were carried out using a macro routine written in SAS Language (Release 9·1, 2002-3).

\section{RESULTS}

Of 157 potentially eligible studies identified by the search strategy, 148 were excluded after screening of the title and abstract because they were not randomised controlled trials, they tested an intervention other than aspirin, the control group did not involve a placebo or no treatment, or the trial did not assess cardiovascular events or mortality. Three additional trials were identified by a hand search of the bibliography of the remaining articles. ${ }^{817} 18$ A total of nine trials, reported in 12 publications, were assessed in full text. Three were excluded as they did not report data on the subset of participants with diabetes. ${ }^{18-20}$ Six randomised controlled trials were finally included, totalling 10117 people with diabetes (fig 1). ${ }^{8-10172122}$ One trial also included a small proportion $(<10 \%)$ of patients with pre-existing established cardiovascular events. ${ }^{21}$ Table 1 outlines the characteristics of the populations and interventions of included randomised controlled trials. The trials were published between 1989 and 2008, carried out in several countries, and enrolled from $2.4 \%{ }^{17}$ to $100 \%$ of participants with diabetes. ${ }^{9102122}$ One study involved only men ${ }^{17}$ and one only women. ${ }^{8}$ Treatment was allocated according to a $2 \times 2$ factorial design with vitamin $\mathrm{E}$ in three studies. ${ }^{8922}$ Four studies were placebo controlled and double blinded. ${ }^{891721}$ Two studies ${ }^{1022}$ were open label. In all studies a blinded committee adjudicated outcomes. The dose of aspirin used in the trials ranged 
from $100 \mathrm{mg}$ on an alternate day basis ${ }^{8}$ up to $650 \mathrm{mg}$ daily. ${ }^{21}$ Follow-up ranged from $3.6^{22}$ to 10.1 years. ${ }^{8}$ Compliance with treatment ranged between $50 \%{ }^{9}$ and $92 \% .^{21}$

\section{Quality assessment}

Based on current standards, the quality of the included studies was suboptimal. Allocation concealment was adequately described in three of the six studies ${ }^{91022}$ and unclear in the remainder. ${ }^{81721}$ All the studies adequately described blinding of outcome assessors and five reported an intention to treat analysis..$^{8-102122}$ Only one study reported funding from industry. ${ }^{22}$ The proportion of participants with diabetes with complete follow-up was reported in three trials and ranged from $92.4 \%$ to $99.5 \% .^{91021}$ For the remaining three trials data for the whole study sample were available but no specific information on the subset of participants with diabetes was reported.

\section{Clinical outcomes}

Major cardiovascular events

No significant reduction in the risk of major cardiovascular events was found with aspirin compared with placebo or no treatment (five studies, 9584 participants, 1258 events; relative risk $0.90,0.81$ to $1.00 ; \mathrm{P}=0.06)$. There was no significant heterogeneity among the studies in this analysis $(\mathrm{Q}=0.94 ; \mathrm{P}=0.92$; $\mathrm{I}^{2}=0 \%$; fig 2). Also, there was no significant decrease in the risk of myocardial infarction with aspirin (six studies, 10117 participants, 834 events; 0.86, 0.61 to $1.21 ; \mathrm{P}=0.37)$. Heterogeneity in this analysis was moderate $\left(\mathrm{Q}=13.21 ; \mathrm{P}=0.02 ; \mathrm{I}^{2}=62.2 \%\right.$; fig 2$)$, which may be explained by the Women's Health Study, which enrolled women only (weight 17\%), and the Physicians' Health Study, which enrolled men only (weight $12 \%$ ). After excluding these studies from our analyses, heterogeneity substantially decreased between trials $\left(\mathrm{Q}=4.18 ; \mathrm{P}=0.24 ; \mathrm{I}^{2}=28.2 \%\right)$.

No significant reduction in the risk of stroke with aspirin compared with placebo or no treatment was found (five studies, 9584 participants, 382 events; $0.83,0.60$ to $1.14 ; \mathrm{P}=0.25)$. Heterogeneity among the trials in this analysis was moderate $(\mathrm{Q}=8.43 ; \mathrm{P}=0.08$; $\mathrm{I}^{2}=52.5 \%$; fig 2), which may be explained by the Women's Health Study (weight 16\%), carried out in women only (after exclusion of the Women's Health Study, $\mathrm{Q}=3.33 ; \mathrm{P}=0.34 ; \mathrm{I}^{2}=9.9 \%$ ).

No significant reduction was found in the risk of death from cardiovascular causes (four studies, 8557

Table 1|Design of trials of aspirin therapy included in meta-analysis

\begin{tabular}{|c|c|c|c|}
\hline Features & PHS 198917 & ETDRS 199221 & PPP 200322 \\
\hline Country & USA & USA & Italy \\
\hline Type of trial & Primary & Mixed & Primary \\
\hline Study design & $\begin{array}{l}\text { Randomised double } \\
\text { blind, placebo controlled } \\
\text { trial }\end{array}$ & $\begin{array}{l}\text { Randomised double } \\
\text { blind, placebo controlled } \\
\text { trial }\end{array}$ & $\begin{array}{l}\text { Randomised open trial } \\
\text { with } 2 \times 2 \text { factorial design }\end{array}$ \\
\hline Patient population & Healthy men & $\begin{array}{l}\text { Men and women with } \\
\text { type } 1 \text { and type } 2 \\
\text { diabetes }\end{array}$ & $\begin{array}{l}\text { Men and women aged } \\
>50 \text { with } \geq 1 \text { risk factors } \\
\text { for cardiovascular } \\
\text { disease }\end{array}$ \\
\hline
\end{tabular}

\begin{tabular}{|c|c|}
\hline WHS 20058 & POPADAD 20089 \\
\hline & cotland \\
\hline
\end{tabular}

Primary

Randomised double

blind, $2 \times 2$ factorial, placebo controlled trial

Healthy women for cardiovascular disease

\begin{tabular}{|c|c|c|c|c|c|c|}
\hline Aspirin dose & 325 mg every other day & $650 \mathrm{mg} /$ day & $100 \mathrm{mg} /$ day & 100 mg every other day & $100 \mathrm{mg} /$ day & 81 or 100 mg per day \\
\hline Primary outcome measure & Cardiovascular mortality & All cause mortality & $\begin{array}{l}\text { Composite end point of } \\
\text { death from } \\
\text { cardiovascular cause, } \\
\text { myocardial infarction, } \\
\text { stroke }\end{array}$ & $\begin{array}{l}\text { Major cardiovascular } \\
\text { events: non-fatal } \\
\text { myocardial infarction, } \\
\text { non-fatal stroke, death } \\
\text { from cardiovascular } \\
\text { causes }\end{array}$ & $\begin{array}{l}\text { Death from coronary } \\
\text { heart disease or stroke, } \\
\text { non-fatal myocardial } \\
\text { infarction or stroke, or } \\
\text { amputation above ankle } \\
\text { for critical limb } \\
\text { ischaemia, death from } \\
\text { coronary heart disease or } \\
\text { stroke }\end{array}$ & $\begin{array}{l}\text { Atherosclerotic events } \\
\text { including fatal or non-fatal } \\
\text { ischaemic heart disease, } \\
\text { fatal or non-fatal stroke, } \\
\text { and peripheral arterial } \\
\text { disease }\end{array}$ \\
\hline $\begin{array}{l}\text { No of people with } \\
\text { diabetes (\% of sample } \\
\text { where appropriate) }\end{array}$ & $533(2.4)$ & 3711 & 1031 & $1027(2.6)$ & 1276 & 2539 \\
\hline Duration of therapy (years) & 5 & 5 & 3.6 & 10.1 & 6.7 & 4.37 \\
\hline $\begin{array}{l}\text { Completeness of follow- } \\
\text { up }(\%)\end{array}$ & $99.7^{*}$ & 94.7 & $99.3^{*}$ & $99.4^{*}$ & 99.5 & 92.4 \\
\hline $\begin{array}{l}\text { Compliance with aspirin } \\
\text { therapy (\%) }\end{array}$ & NA & 91.8 & 71.8 & NA & 50 & 90 \\
\hline Men (\%) & 100 & 56.5 & 48.2 & - & 44.1 & 55 \\
\hline Women (\%) & - & 43.5 & 51.8 & 100 & 55.9 & 45 \\
\hline Mean (SD) age (years) & NA & NA & $64.3(7.5)$ & NA & NA & $65(10)$ \\
\hline
\end{tabular}

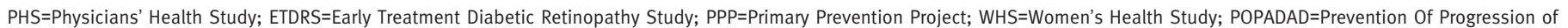
Arterial Disease And Diabetes; JPAD=Japanese Primary Prevention of Atherosclerosis with Aspirin for Diabetes; NA=not available.

*Data refer to whole sample. 
participants, 626 events; $0.94,0.72$ to $1.23 ; \mathrm{P}=0.68$ ) with aspirin compared with placebo or no treatment (fig 2). Heterogeneity was moderate in this analysis $\left(\mathrm{Q}=6.92 ; \mathrm{P}=0.07 ; \mathrm{I}^{2}=56.6 \%\right)$. This heterogeneity may be explained partly by the Japanese Primary Prevention of Atherosclerosis with Aspirin for Diabetes (JPAD) study (4\% weight), which enrolled Japanese patients only (after exclusion of JPAD, Q $=2.50$; $\left.\mathrm{P}=0.29 ; \mathrm{I}^{2}=20.1 \%\right)$.

\section{All cause mortality}

The risk of all cause mortality showed no significant reduction with aspirin compared with placebo or no

\begin{tabular}{|c|c|c|c|}
\hline & \multicolumn{2}{|c|}{ No of events/No in group } & \multirow[b]{2}{*}{$\begin{array}{c}\text { Relative risk } \\
(95 \% \mathrm{CI})\end{array}$} \\
\hline & Aspirin & $\begin{array}{l}\text { Control or } \\
\text { placebo }\end{array}$ & \\
\hline \multicolumn{3}{|c|}{ Major cardiovascular events } & \\
\hline$J_{P A D}{ }^{10}$ & $68 / 1262$ & $86 / 1277$ & $\rightarrow$ \\
\hline POPADAD ${ }^{9}$ & $105 / 638$ & $108 / 638$ & - \\
\hline $\mathrm{WHS}^{8}$ & $58 / 514$ & $62 / 513$ & $\rightarrow$ \\
\hline $\mathrm{PPP}^{22}$ & $20 / 519$ & $22 / 512$ & $\rightarrow-$ \\
\hline ETDRS $^{21}$ & $350 / 1856$ & $379 / 1855$ & $\Rightarrow$ \\
\hline Total & $601 / 4789$ & $657 / 4795$ & $\bullet$ \\
\hline
\end{tabular}

\section{Relative risk (95\% CI)}

0.80 (0.59 to 1.09$)$ 0.97 (0.76 to 1.24$)$ $0.90(0.63$ to 1.29$)$ 0.90 (0.50 to 1.62$)$ 0.90 (0.78 to 1.04$)$ $0.90(0.81$ to 1.00$)$

\section{Myocardial infarction}

$\begin{array}{lcc}\text { JPAD }^{10} & 28 / 1262 & 14 / 1277 \\ \text { POPADAD }^{9} & 90 / 638 & 82 / 638 \\ \text { WHS }^{8} & 36 / 514 & 24 / 513 \\ \text { PPP }^{22} & 5 / 519 & 10 / 512 \\ \text { ETDRS }^{21} & 241 / 1856 & 283 / 1855 \\ \text { PHS }^{17} & 11 / 275 & 26 / 258 \\ \text { Total } & 395 / 5064 & 439 / 5053\end{array}$

Total

$395 / 5064$

$439 / 5053$

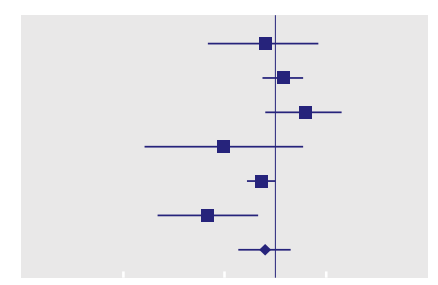

0.87 (0.40 to 1.87$)$ $1.10(0.83$ to 1.45$)$ 1.48 (0.88 to 2.49$)$ 0.49 (0.17 to 1.43$)$ 0.82 (0.69 to 0.98$)$ $0.40(0.20$ to 0.79$)$ $0.86(0.61$ to 1.21$)$

\section{Stroke}

$0.89(0.54$ to 1.46$)$ 0.74 (0.49 to 1.12$)$ $0.46(0.25$ to 0.85$)$ 0.89 (0.36 to 2.17$)$ 1.17 (0.87 to 1.58$)$ 0.83 (0.60 to 1.14$)$
JPAD $^{10}$

POPADAD

$12 / 1262$

$32 / 1277$

WHS $^{8}$

$\mathrm{PPP}^{22}$

ETDRS $^{21}$

$37 / 638$

$15 / 514$

$50 / 638$

$31 / 513$

$9 / 519$

$10 / 512$

$92 / 1856$

$78 / 1855$

Total

$181 / 4789$

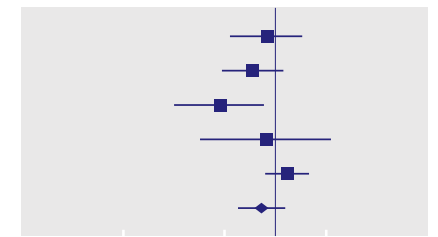

Death from cardiovascular causes

JPAD $^{10}$ $1 / 1262$

POPADAD

$43 / 638$

PPP $^{22}$

ETDRS $^{21}$

$10 / 519$

Total

$244 / 1856$

$298 / 4275$
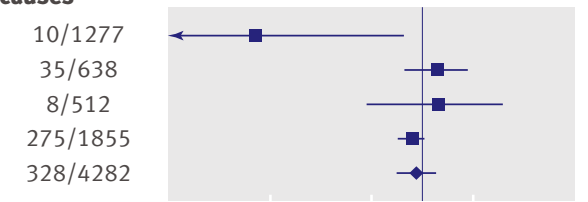

All cause mortality

$\begin{array}{lcc}\text { JPAD }^{10} & 34 / 1262 & 38 / 1277 \\ \text { POPADAD }^{9} & 94 / 638 & 101 / 638 \\ \text { PPP }^{22} & 25 / 519 & 20 / 512 \\ \text { ETDRS }^{21} & 340 / 1856 & 366 / 1855 \\ \text { Total } & 493 / 4275 & 525 / 4282\end{array}$

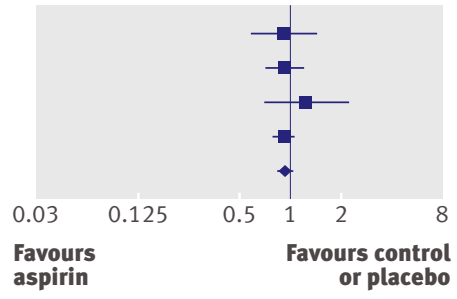

0.10 (0.01 to 0.79$)$ 1.23 (0.80 to 1.89$)$ $1.23(0.49$ to 3.10$)$ 0.87 (0.73 to 1.04$)$ 0.94 (0.72 to 1.23$)$

$0.90(0.57$ to 1.14$)$ $0.93(0.72$ to 1.21$)$ 1.23 (0.69 to 2.19 ) 0.91 (0.78 to 1.06$)$ 0.93 (0.82 to 1.05$)$

Fig 2 Effect of aspirin therapy on primary prevention of major cardiovascular events, myocardial infarction, stroke, death from cardiovascular causes, and all cause mortality in participants with diabetes. JPAD=Japanese Primary Prevention of Atherosclerosis with Aspirin for Diabetes; POPADAD=Prevention Of Progression of Arterial Disease And Diabetes;

WHS=Women's Health Study; PPP=Primary Prevention Project; ETDRS=Early Treatment Diabetic Retinopathy Study. Number in group have been reported as provided by trialists or estimated from any available data in the publications treatment (four studies, 8557 participants, 1018 events; 0.93 , 0.82 to $1.05 ; \mathrm{P}=0.22$; fig 2 ). Heterogeneity was not significant among studies in this analysis $(\mathrm{Q}=1.02$; $\left.\mathrm{P}=0.80 ; \mathrm{I}^{2}=0 \%\right)$.

Side effects: bleeding, gastrointestinal symptoms, cancer Table 2 presents the summary estimates of the effects of aspirin compared with placebo or no treatment on any bleeding, gastrointestinal bleeding, gastrointestinal symptoms, and cancer. There was no statistically significant increase in the risk of any of these outcomes with aspirin therapy compared with placebo or no treatment.

\section{Investigation of sources of heterogeneity}

Heterogeneity by dose of aspirin, duration of treatment, compliance with treatment, and allocation concealment was explored by subgroup analysis. No evidence of effect modification was evident by any of these covariates for any outcome except for stroke (table 3). The risk of stroke was significantly reduced in trials where an aspirin dose of $100 \mathrm{mg}$ or less per day was used compared with trials where more than $100 \mathrm{mg} /$ day was used (P for interaction=0.02). Similarly, the risk of stroke was significantly lower with aspirin than with placebo or no treatment in trials of more than five years' duration compared with trials of five or fewer years' duration (P for interaction $=0.01$ ). Compliance with treatment was also a significant effect modifier $(\mathrm{P}$ for interaction $=0.02)$.

We also explored heterogeneity by sex. Aspirin significantly reduced the risk of myocardial infarction among men by $43 \%$ (three studies, 3126 participants, 265 events; $0.57,0.34$ to $0.94 ; \mathrm{P}=0.03)$. In contrast, no effect of aspirin was noted among women (three studies, 3176 participants, 245 events; $1.08,0.71$ to 1.65 ; $\mathrm{P}=0.71$ ) ( $\mathrm{P}$ for interaction by sex $=0.056$; fig 3 ).

No significant reduction in the risk of stroke with aspirin compared with placebo or no treatment was found in men (two studies, 2593 participants, 93 events; $1.11,0.75$ to $1.64 ; \mathrm{P}=0.61$ ) or in women (three studies, 3176 participants, 127 events; $0.75,0.37$ to 1.53; $\mathrm{P}=0.43$; fig 3 ) ( $\mathrm{P}$ for interaction by $\mathrm{sex}=0.34$ ).

\section{DISCUSSION}

A clear benefit of aspirin in the primary prevention of major cardiovascular events or mortality in people with diabetes could not be identified in our meta-analysis. We found no significant reduction in the risk of major cardiac events with aspirin compared with placebo or no treatment. Confidence intervals in this analysis argue for a potential benefit of aspirin, compatible with that observed in other high risk populations, but the benefit was small at best or trials were underpowered to detect it with sufficient precision.

We were also not able to show a significant reduction in the risk of all cause mortality with aspirin compared with placebo or no treatment. Taken together these data indicate either low efficacy of aspirin in people with diabetes or insufficient evidence. In many analyses there was a significant heterogeneity, explored 
by subgroup analysis for specific end points (myocardial infarction and stroke) based on selective exposures. Subgroup analysis by sex confirmed that aspirin significantly reduced the risk of myocardial infarction in men by $43 \%$, whereas no benefit was found in women. There was no statistically significant reduction in the risk of stroke with aspirin in men and in women, but there were opposite trends across these two subgroups - that is, an increased risk in men and a decreased risk in women. Finally, we found no significant increase in the risk of bleeding and cancer with aspirin compared with placebo or no treatment.

\section{Comparison with existing data}

Our data are coherent with a previous meta-analysis on antiplatelet therapy for the prevention of major cardiovascular events, showing a clear benefit for the overall population ( $>140000$ people, $22 \%$ risk reduction), but no statistically significant benefit in the subgroup of people with diabetes $\left(\mathrm{n}=5000,7 \%\right.$ risk reduction). ${ }^{2}$ The potential reasons for lower efficacy of aspirin in people with diabetes compared with other high risk populations have been explored. ${ }^{23}$ An increasing amount of data suggest that factors specific to diabetes, including hyperglycaemia, hyperinsulinaemia, increased oxidative stress, and advanced glycosylation end products, may up-regulate humoral, cellular inflammatory, and thrombogenic reactions thereby playing a part in atherothrombosis. ${ }^{24}$ It is plausible that the clinical failure of aspirin in diabetes might be attributed to mechanisms unrelated to the primary biochemical effect of aspirin on its main pharmacological targets - that is, synthesis of thromboxane $\mathrm{A}_{2}$ and platelet activation. ${ }^{24}$ These findings support the view that that people with diabetes may not simply be a subgroup of patients at high risk of cardiovascular events but a separate entity, with additional factors playing an important part in determining the efficacy of treatment.

One possibility is that the trials lacked power to detect an effect in people with diabetes if it exists. The results of a recently published collaborative meta-analysis by the Antithrombotic Trialists' Collaboration argue in that direction, suggesting a limited efficacy of aspirin in primary prevention in people without diabetes. ${ }^{25}$

A differential effect of aspirin in men and women was also described in a previous meta-analysis of primary prevention trials ${ }^{26}$ but not confirmed in the

Table 2 |Comparative risk of developing drug related side effects with aspirin compared with placebo or no treatment

\begin{tabular}{lccc} 
Side effect & $\begin{array}{c}\text { No of trials reporting } \\
\text { outcome }\end{array}$ & No of patients & Relative risk $(95 \% \mathrm{Cl})$ \\
\hline Any bleeding & 3 & 7281 & $2.50(0.76$ to 8.21$)$ \\
\hline Gastrointestinal bleeding & 3 & 4846 & $2.11(0.64$ to 6.95$)$ \\
\hline Gastrointestinal symptoms* & 2 & 3815 & $5.09(0.08$ to 314.39$)$ \\
\hline Cancer & 2 & 2307 & $0.84(0.62$ to 1.14$)$ \\
\hline
\end{tabular}

${ }^{*}$ As generically reported by authors. recent Antithrombotic Trialists' Collaboration metaanalysis of both primary and secondary prevention trials analysed separately. ${ }^{25}$ An effect was evident in all participants enrolled in the Women's Health Study. ${ }^{8}$ It remains to be established whether a true differential "district" effect exists in men and women, caused by mechanisms still to be elucidated, or that the effect is simply the result of a play of chance or a type II statistical error or lack of power.

\section{Strengths and limitations of the meta-analysis}

This is the first and largest meta-analysis of trials of aspirin in only people with diabetes $(>10000$, twice that of previously published data). ${ }^{7}$ A strength of this investigation is that it represents a comprehensive review, based on a predefined study protocol and rigid inclusion criteria for randomised trials only, and deriving from a comprehensive search of Medline and the Cochrane central register of controlled trials. We evaluated the efficacy of aspirin on a wide range of outcomes, including for the first time deaths from cardiovascular events and all cause mortality. The Early Treatment Diabetic Retinopathy Study (ETDRS), the largest study included in our meta-analysis, involved a small proportion of people with previous cardiovascular events, which could not be extrapolated and excluded from the primary analysis. The overall results were not materially affected by a sensitivity analysis excluding this study from our analysis (non-differential effect modification). We also could not include some data of trials that enrolled people with diabetes where separate results for this subgroup were not available. ${ }^{1920}$ Data extraction, data analysis, and quality assessments of the methods were done by two independent investigators, and consistency was checked with an arbitrator. The main weakness of this study was the paucity of high quality randomised trials. A possible explanation for some of our findings may be the lack of adequate power in existing trials to detect effects of aspirin, either because the efficacy of aspirin was moderate to low in itself or because diabetic status was an effect modifier.

In addition, we had concerns with the methodological quality of the existing trials. Half of the studies evaluated failed to specify whether randomisation allocation was concealed and some were relatively outdated and hardly applicable in current practice, where patterns for the management of cardiovascular risk factors in diabetes have changed. We also could not explore the incremental benefit of aspirin over and above other cointerventions, including statins, angiotensin converting enzyme inhibitors, and strict metabolic control.

Heterogeneity between trials was found in some analyses, which most likely reflects a sex interaction, but other causes of heterogeneity could not be explored owing to the scarcity of data. These issues reduce the strength of the conclusions that have been drawn in this review. 
Table 3| Subgroup analysis of sources of variability for outcomes analysed. Values are relative risks ( $95 \%$ confidence intervals) and number of studies

\begin{tabular}{|c|c|c|c|c|c|c|c|c|c|c|}
\hline Variable & $\begin{array}{l}\text { Major } \\
\text { cardio- } \\
\text { vascular } \\
\text { events }\end{array}$ & P value* & $\begin{array}{l}\text { Myocardial } \\
\text { infarction }\end{array}$ & P value* & Stroke & P value* & $\begin{array}{l}\text { Death from } \\
\text { cardio- } \\
\text { vascular } \\
\text { causes }\end{array}$ & P value* & $\begin{array}{c}\text { Total } \\
\text { mortality }\end{array}$ & P value* \\
\hline \multicolumn{11}{|l|}{ Aspirin dose: } \\
\hline$\leq 100 \mathrm{mg} /$ day & $\begin{array}{c}0.91(0.78 \text { to } \\
1.07) ; n=4\end{array}$ & \multirow{2}{*}{0.90} & $\begin{array}{c}1.08(0.71 \text { to } \\
1.65) ; n=4\end{array}$ & \multirow{2}{*}{0.13} & $\begin{array}{c}0.71(0.53 \text { to } \\
0.94) ; n=4\end{array}$ & \multirow{2}{*}{0.02} & $\begin{array}{c}0.76(0.24 \text { to } \\
2.46) ; n=3\end{array}$ & \multirow{2}{*}{0.90} & $\begin{array}{c}0.98(0.77 \text { to } \\
1.24) ; \mathrm{n}=2\end{array}$ & \multirow{2}{*}{0.62} \\
\hline$>100$ mg/day & $\begin{array}{c}0.90(0.78 \text { to } \\
1.04) ; \mathrm{n}=1\end{array}$ & & $\begin{array}{c}0.66(0.40 \text { to } \\
1.07) ; n=2\end{array}$ & & $\begin{array}{c}1.17 \text { (0.87 to } \\
1.58) ; \mathrm{n}=1\end{array}$ & & $\begin{array}{c}0.87(0.16 \text { to } \\
4.86) ; n=1\end{array}$ & & $\begin{array}{c}0.91(0.78 \text { to } \\
1.06) ; \mathrm{n}=1\end{array}$ & \\
\hline
\end{tabular}

Duration of

therapy:

\begin{tabular}{|c|c|c|c|c|c|c|c|c|c|c|}
\hline$\leq 5$ years & $\begin{array}{c}0.88(0.77 \text { to } \\
1.00) ; n=3\end{array}$ & \multirow{2}{*}{0.45} & $\begin{array}{l}0.72(0.48 \text { to } \\
1.07) ; n=4\end{array}$ & \multirow{2}{*}{0.13} & $\begin{array}{c}1.07(0.84 \text { to } \\
1.37) ; n=3\end{array}$ & \multirow{2}{*}{0.01} & $\begin{array}{c}0.87(0.73 \text { to } \\
1.03) ; n=3\end{array}$ & \multirow{2}{*}{0.14} & $\begin{array}{c}0.93(0.80 \text { to } \\
1.07) ; n=2\end{array}$ & \multirow{2}{*}{0.99} \\
\hline$>5$ years & $\begin{array}{c}0.96(0.79 \text { to } \\
1.17) ; n=2\end{array}$ & & $\begin{array}{c}1.17(0.72 \text { to } \\
1.91) ; n=2\end{array}$ & & $\begin{array}{c}0.60(0.42 \text { to } \\
0.87) ; n=2\end{array}$ & & $\begin{array}{c}1.23(0.80 \text { to } \\
1.89) ; n=1\end{array}$ & & $\begin{array}{c}0.93(0.72 \text { to } \\
1.21) ; n=1\end{array}$ & \\
\hline \multicolumn{11}{|l|}{ Compliance: } \\
\hline$<90 \%$ & $\begin{array}{c}0.98(0.79 \text { to } \\
1.21) ; n=2\end{array}$ & \multirow{2}{*}{0.72} & $\begin{array}{c}0.77(0.31 \text { to } \\
1.92) ; n=2\end{array}$ & \multirow{2}{*}{0.91} & $\begin{array}{c}0.74(0.49 \text { to } \\
1.12) ; n=2\end{array}$ & \multirow{2}{*}{0.02} & $\begin{array}{c}1.23(0.83 \text { to } \\
1.82) ; n=2\end{array}$ & \multirow{2}{*}{0.10} & $\begin{array}{c}0.98(0.77 \text { to } \\
1.24) ; n=2\end{array}$ & \multirow{2}{*}{0.62} \\
\hline$\geq 90 \%$ & $\begin{array}{c}0.88(0.77 \text { to } \\
1.01) ; n=2\end{array}$ & & $\begin{array}{c}0.99(0.42 \text { to } \\
2.37) ; n=2\end{array}$ & & $\begin{array}{c}1.09(0.84 \text { to } \\
1.41) ; n=2\end{array}$ & & $\begin{array}{c}0.86(0.72 \text { to } \\
1.02) ; n=2\end{array}$ & & $\begin{array}{c}0.91(0.78 \text { to } \\
1.06) ; n=1\end{array}$ & \\
\hline
\end{tabular}

Allocation

concealment:

\begin{tabular}{|c|c|c|c|c|c|c|c|c|c|c|}
\hline Adequate & $\begin{array}{c}0.92(0.77 \text { to } \\
1.09) ; n=3\end{array}$ & \multirow{2}{*}{0.88} & $\begin{array}{c}0.92(0.49 \text { to } \\
1.74) ; n=3\end{array}$ & \multirow{2}{*}{0.78} & $\begin{array}{c}0.81(0.48 \text { to } \\
1.35) ; n=3\end{array}$ & \multirow{2}{*}{0.99} & $\begin{array}{c}0.76(0.24 \text { to } \\
2.46) ; n=3\end{array}$ & \multirow{2}{*}{0.90} & $\begin{array}{c}0.98(0.77 \text { to } \\
1.24) ; n=2\end{array}$ & \multirow{2}{*}{0.62} \\
\hline Unclear & $\begin{array}{c}0.90(0.79 \text { to } \\
1.03) ; n=2\end{array}$ & & $\begin{array}{c}0.82(0.47 \text { to } \\
1.42) ; n=3\end{array}$ & & $\begin{array}{c}0.81(0.46 \text { to } \\
1.43) ; n=2\end{array}$ & & $\begin{array}{c}0.87(0.16 \text { to } \\
4.86) ; n=1\end{array}$ & & $\begin{array}{c}0.91(0.78 \text { to } \\
1.06) ; n=1\end{array}$ & \\
\hline
\end{tabular}

*For interaction.

\section{No of events/No in group}

Aspirin Control or

Myocardial infarction

\section{Men}

PPP $^{22}$

ETDRS $^{21}$

$\mathrm{PHS}^{17}$

Total

$3 / 246$
$89 / 1031$
$11 / 275$
$103 / 1552$

placebo

Relative risk

(95\% Cl)

$8 / 251$
$128 / 1065$
$26 / 258$
$162 / 1574$

Women

$\mathrm{WHS}^{8}$

$\mathrm{PPP}^{22}$

ETDRS $^{21}$

$36 / 514$

$2 / 273$

$81 / 825$

$119 / 1612$

$24 / 513$

$2 / 261$

$100 / 790$

$126 / 1564$

\section{Relative risk} (95\% CI)

\section{Stroke}

Men

PPP $^{22}$

ETDRS $^{21}$

Total

Women

WHS $^{8}$

PPP $^{22}$

ETDRS $^{21}$

Total

$$
\begin{gathered}
4 / 246 \\
45 / 1031 \\
49 / 1277
\end{gathered}
$$

$$
15 / 514
$$$$
5 / 273
$$

$38 / 825$

$58 / 1612$
42/1065

44/1316

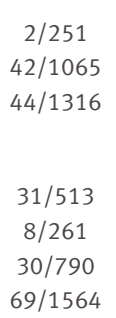

$69 / 1564$

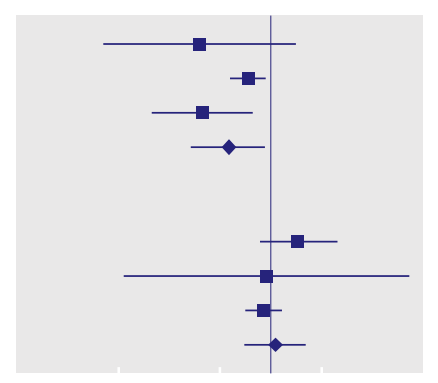

0.38 (0.10 to 1.43$)$ 0.74 (0.59 to 0.94$)$ 0.40 (0.20 to 0.79$)$ 0.57 (0.34 to 0.94)

1.48 (0.88 to 2.49$)$ 0.96 (0.14 to 6.74) 0.91 (0.70 to 1.18$)$ 1.08 (0.71 to 1.65$)$

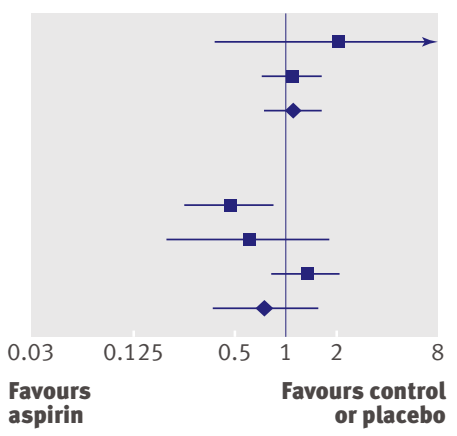

2.04 (0.38 to 11.04) 1.07 (0.71 to 1.61$)$ 1.11 (0.75 to 1.64$)$

$0.46(0.25$ to 0.85$)$ 0.60 (0.20 to 1.80$)$ 1.31 (0.83 to 2.08$)$ 0.75 (0.37 to 1.53$)$
Fig 3 | Effect of aspirin therapy on primary prevention of myocardial infarction and stroke among men and women with diabetes. PPP=Primary Prevention Project; ETDRS=Early Treatment Diabetic Retinopathy Study; PHS=Physicians' Health Study; WHS=Women's Health Study. Number in group have been reported as provided by trialists or estimated from any available data in the publications
Implications for clinical practice

Taken together, our findings do not support strong recommendations to use aspirin in the primary prevention of cardiovascular events in all people with diabetes. A decision should still be taken on an individual patient basis, after careful evaluation of a trade-off between benefits and harms, particularly the risk of major bleeding. Although not confirmed in trials of only people with diabetes, several studies in the general population have shown an absolute excess of about one to two major bleeding complications for every 1000 people treated with low doses of aspirin for one year. The risk of bleeding increases sharply in people aged over 70. ${ }^{27}$ The fact that our meta-analysis could not confirm this in trials of aspirin in only people with diabetes is possibly due to the trials themselves being underpowered to detect this relatively rare event. From recent studies it can be estimated that the incidence of major cardiovascular events in people with diabetes and without previous cardiovascular events is between 10 and 20 per 1000 person years. ${ }^{28-31}$ Assuming a relative risk reduction associated with aspirin treatment of about 10\%, as suggested by our meta-analysis, 1000 people need to be treated for one year to prevent one or two major cardiovascular events. Therefore the expected benefits might not exceed the risk of major bleedings, particularly among people at low cardiovascular risk (that is, $<20 \%$ over 10 years), or among older patients $(>70$ years) at high risk of bleeding.

\section{Implications for research}

Two trials, A Study of Cardiovascular Events in Diabetes (ASCEND, International Standard Randomised 


\section{WHAT IS ALREADY KNOWN ON THIS TOPIC}

People with diabetes are at an increased risk of cardiovascular disease than those without diabetes

Most guidelines recommend the use of aspirin in the primary prevention of major cardiovascular events in people with diabetes

The role of aspirin in the primary prevention of major cardiovascular events in diabetes remains controversial

\section{WHAT THIS STUDY ADDS}

This meta-analysis suggests that the benefit of aspirin in the primary prevention of major cardiovascular events or death in people with diabetes may be lower than in other high risk populations

Aspirin significantly reduced the risk of myocardial infarction in men by $43 \%$, whereas no benefit was found in women

The expected benefits of aspirin in people with diabetes might not exceed the risk of major bleedings, particularly among those at low cardiovascular risk ( $220 \%$ over 10 years), or among older patients ( $>70$ years) at high risk of bleeding take responsibility for the integrity of the data and the accuracy of the data analysis.

Funding: None.

Competing interests: None declared.

Ethical approval: Not required.

Data sharing: No additional data available.

1 IDF Clinical Guidelines Task Force. Global guideline for type 2 diabetes: recommendations for standard, comprehensive, and minimal care. Diabet Med 2006;23:579-93.

2 Buse JB, Ginsberg HN, Bakris GL, Clark NG, Costa F, Eckel R, et al. American Heart Association; American Diabetes Association. Primary prevention of cardiovascular diseases in people with diabetes mellitus: a scientific statement from the American Heart Association and the American Diabetes Association. Circulation 2007;115:114-26.

3 Rydén L, Standl E, Bartnik M, Van den Berghe G, Betteridge J, de Boer MJ, et al. Task Force on Diabetes and Cardiovascular Diseases of the European Society of Cardiology (ESC); European Association for the Study of Diabetes (EASD). Guidelines on diabetes, prediabetes, and cardiovascular diseases: executive summary. The Task Force on Diabetes and Cardiovascular Diseases of the European Society of Cardiology (ESC) and of the European Association for the Study of Diabetes (EASD). Eur Heart J 2007;28:88-136.

4 Rodbard HW, Blonde L, Braithwaite SS, Brett EM, Cobin RH, Handelsman Y, et al.; AACE Diabetes Mellitus Clinical Practice Guidelines Task Force. American Association of Clinical Endocrinologists medical guidelines for clinical practice for the management of diabetes mellitus. Endocr Pract 2007;13(suppl 1):1-68. Aspirin and Simvastatin Combination for Cardiovascular Events Prevention Trial in Diabetes (ACCEPT-D, Current Controlled Trials ISRCTN48110081), ${ }^{32}$ are ongoing and will enrol more than 15000 participants. These will help clarify the role of aspirin in the primary prevention of cardiovascular disease in people with diabetes and may be pooled with existing data. The large number of events and participants will allow adequately powered subgroup analyses for specific populations such as elderly patients, women, or people with different severity of diabetes. Meanwhile, a better understanding of the pathophysiological mechanisms involved in the response of platelets to aspirin may also contribute to the identification of those who are more likely to benefit from antiplatelet treatment. Whether additional factors, such as poor metabolic control, degree of insulin resistance, or duration of diabetes could play an important part in modulating platelet response to aspirin remains a key priority for our future research agenda in diabetes and cardiovascular diseases.

\section{Conclusion}

Taken together our findings contrast with prevailing beliefs and existing summaries of evidence and guidelines based on trials done in populations at higher risk of cardiac events. We cannot recommend using aspirin in the primary prevention of cardiovascular events in all patients with diabetes without additional evidence and contend that there is a strong case for awaiting the results of the ASCEND and ACCEPT-D trials before policy making in this incompletely explored area.

Contributors: AN was involved in the concept and design of the review, analysis and interpretation of data, and writing the final manuscript. GDB and MS were equally involved in the quality assessment of studies, data extraction, and writing of the manuscript. FP and GG were involved in data analysis. GS was involved in critical revision for intellectual content and interpretation of data and assisted with writing the final manuscript. GT gave critical revision of the manuscript for important intellectual content. All authors approved the manuscript for publication. AN is the guarantor. All authors had full access to all of the data in the study and can
5 Bhattacharyya OK, Shah BR, Booth GL. Management of cardiovascular disease in patients with diabetes: the 2008 Canadian Diabetes Association guidelines. CMA/ 2008;179:920-6.

6 Nicolucci A, De Berardis G, Sacco M, Tognoni G. AHA/ADA vs ESC/ EASD recommendations on aspirin as a primary prevention strategy in people with diabetes: how the same data generate divergent conclusions. Eur Heart / 2007; 28:1925-7.

7 Antithrombotic Trialists' Collaboration. Collaborative meta-analysis of randomised trials of antiplatelet therapy for prevention of death, myocardial infarction, and stroke in high risk patients. $B M$ 2002;324:71-86.

8 Ridker PM, Cook NR, Lee IM, Gordon D, Gaziano JM, Manson JE, et al. A randomized trial of low-dose aspirin in the primary prevention of cardiovascular disease in women. $N$ Engl J Med 2005;352:1293-304.

9 Belch J, MacCuish A, Campbell I, Cobbe S, Taylor R, Prescott R, et al. The prevention of progression of arterial disease and diabetes (POPADAD) trial: factorial randomised placebo controlled trial of aspirin and antioxidants in patients with diabetes and asymptomatic peripheral arterial disease. BMJ 2008;337:a1840.

10 Ogawa H, Nakayama M, Morimoto T, Uemura S, Kanauchi M, Doi N, et al. Japanese Primary Prevention of Atherosclerosis With Aspirin for Diabetes (JPAD) Trial Investigators. Low-dose aspirin for primary prevention of atherosclerotic events in patients with type 2 diabetes: a randomized controlled trial. JAMA 2008;300:2134-41.

11 Hiatt WR. Aspirin for prevention of cardiovascular events. BMJ 2008;337:a1806.

12 Nicolucci A. Aspirin for primary prevention of cardiovascular events in diabetes: still an open question. JAMA 2008;300:2180-1.

13 Farkouh ME, Fuster V. Diabetes and aspirin: beware of underpowered negative trials. Nat Clin Pract Cardiovasc Med 2009;6:1.

14 Dickersin K, Scherer R, Lefebvre C. Identifying relevant studies for systematic reviews. BMJ 1994;309:1286-91.

15 Higgins JP, Thompson SG, Deeks JJ, Altman DG. Measuring inconsistency in meta-analyses. BMJ 2003;327:557-60.

16 Van Houwelingen HC, Arends LR, Stijnen T. Advanced methods in meta-analysis: multivariate approach and meta-regression. Stat Med 2002;21:589-24.

17 Steering Committee of the Physicians' Health Study Research Group. Final report on the aspirin component of the ongoing Physicians' Health Study. N EnglJ Med 1989;321:129-35.

18 Peto R, Gray R, Collins R, Wheatley K, Hennekens C, Jamrozik K, et al. Randomised trial of prophylactic daily aspirin in British male doctors. BMJ (Clin Res Ed) 1988;296:313-6.

19 Hansson L, Zanchetti A, Carruthers SG, Dahlöf B, Elmfeldt D, Julius S, et al. Effects of intensive blood-pressure lowering and low-dose aspirin in patients with hypertension: principal results of the Hypertension Optimal Treatment (HOT) randomised trial. HOT Study Group. Lancet 1998;351:1755-62.

20 Critical Leg Ischaemia Prevention Study (CLIPS) Group, Catalano M, Born G, Peto R. Prevention of serious vascular events by aspirin amongst patients with peripheral arterial disease: randomized, double-blind trial. J Intern Med 2007;261:276-84. 
21 ETDRS Investigators. Aspirin effects on mortality and morbidity in patients with diabetes mellitus. Early Treatment Diabetic Retinopathy Study report 14. JAMA 1992;268:1292-300.

22 Sacco M, Pellegrini F, Roncaglioni MC, Avanzini F, Tognoni G, Nicolucci A. Primary prevention of cardiovascular events with lowdose aspirin and vitamin $E$ in type 2 diabetic patients: results of the Primary Prevention Project (PPP) trial. Diabetes Care 2003;26:3264-72.

23 Ajjan R, Storey RF, Grant PJ. Aspirin resistance and diabetes mellitus. Diabetologia 2008;51:385-90.

24 Evangelista V, Totani L, Rotondo S, Lorenzet R, Tognoni G, De Berardis G, et al. Prevention of cardiovascular disease in type-2 diabetes: how to improve the clinical efficacy of aspirin. Thromb Haemost 2005;93:8-16.

25 Antithrombotic Trialists' (ATT) Collaboration, Baigent C, Blackwell L, Collins R, Emberson J, Godwin J, et al. Aspirin in the primary and secondary prevention of vascular disease: collaborative metaanalysis of individual participant data from randomised trials. Lancet 2009;373:1849-60.

26 Berger JS, Roncaglioni MC, Avanzini F, Pangrazzi I, Tognoni G, Brown DL. Aspirin for the primary prevention of cardiovascular events in women and men: a sex-specific meta-analysis of randomized controlled trials. JAMA 2006;295:306-13.
27 Patrono C, García Rodríguez LA, Landolfi R, Baigent C. Low-dose aspirin for the prevention of atherothrombosis. N Engl J Med 2005;353:2373-83.

28 Avogaro A, Giorda C, Maggini M, Mannucci E, Raschetti R, Lombardo F, et al. Incidence of coronary heart disease in type 2 diabetic men and women: impact of microvascular complications, treatment, and geographic location. Diabetes Care 2007;30:1241-7.

29 Howard BV, Best LG, Galloway JM, Howard WJ, Jones K, Lee ET, et al. Coronary heart disease risk equivalence in diabetes depends on concomitant risk factors. Diabetes Care 2006;29:391-7.

30 Lee CD, Folsom AR, Pankow JS, Brancati FL. Atherosclerosis Risk in Communities (ARIC) Study Investigators. Cardiovascular events in diabetic and nondiabetic adults with or without history of myocardial infarction. Circulation 2004;109:855-60.

31 Wannamethee SG, Shaper AG, Lennon L. Cardiovascular disease incidence and mortality in older men with diabetes and in men with coronary heart disease. Heart 2004;90:1398-403.

32 De Berardis G, Sacco M, Evangelista V, Filippi A, Giorda CB, Tognoni G, et al. ACCEPT-D Study Group. Aspirin and Simvastatin Combination for Cardiovascular Events Prevention Trial in Diabetes (ACCEPT-D): design of a randomized study of the efficacy of low-dose aspirin in the prevention of cardiovascular events in subjects with diabetes mellitus treated with statins. Trials 2007;8:21-9.

Accepted: 9 September 2009 